\title{
Application of a risk stratification tool for familial hypercholesterolaemia in primary care: an observational cross-sectional study in an unselected urban population
}

\author{
Chris Carvalho (D) , ' Crystal Williams, ${ }^{1}$ Zahra Raisi-Estabragh (D) , ${ }^{2,3}$ Stuart Rison (D) , \\ Riyaz S Patel (D) , ${ }^{2,3}$ Adam Timmis (D) ,'3 John Robson (D) ${ }^{1}$
}

\begin{abstract}
- Additional supplemental material is published online only. To view, please visit the journal online (http://dx.doi. org/10.1136/heartjnl-2020318714)
\end{abstract}

${ }^{1}$ Institute of Population Health Sciences, Queen Mary University of London, London, UK ${ }^{2}$ Barts Heart Centre, Saint Bartholomew's Hospital, London, UK

'William Harvey Institute, NIHR Barts Biomedical Research Centre, Queen Mary University of London, London, UK

Correspondence to Dr John Robson, Institute of Population Health Sciences, Queen Mary University of London, London E1 2AB, UK ; j.robson@qmul.ac.uk

Received 25 November 2020 Revised 17 March 2021 Accepted 22 March 2021 Published Online First 20 May 2021

\section{Linked}

- http://dx.doi.org/10.1136/ heartjnl-2020-318813

Check for updates

(c) Author(s) (or their employer(s)) 2021. No commercial re-use. See rights and permissions. Published by BMJ.

To cite: Carvalho C,

Williams C, Raisi-

Estabragh Z, et al. Heart

2021:107:1220-1225.

\section{ABSTRACT}

Objective The Familial Hypercholesterolaemia Case Ascertainment Tool (FAMCAT) has been proposed to enhance case finding in primary care. In this study, we test application of the FAMCAT algorithm to describe risks of familial hypercholesterolaemia $(\mathrm{FH})$ in a large unselected and ethnically diverse primary care cohort. Method We studied patients aged 18-65 years from three contiguous areas in inner London. We retrospectively applied the FAMCAT algorithm to routine primary care data and estimated the numbers of possible cases of FH and the potential service implications of subsequent investigation and management.

Results Of the 777128 patients studied, the FAMCAT score estimated between 11736 and 23798 (1.5\%$3.1 \%$ ) individuals were likely to have $\mathrm{FH}$, depending on an assumed FH prevalence of 1 in 250 or 1 in 500, respectively. There was over-representation of individuals of South Asian ethnicity among those likely to have $\mathrm{FH}$, with this cohort making up $41.9 \%-45.1 \%$ of the total estimated cases, a proportion which significantly exceeded their $26 \%$ representation in the study population.

Conclusions We have demonstrated feasibility of application of the FAMCAT as an aid to case finding for $\mathrm{FH}$ using routinely recorded primary care data. Further research is needed on validity of the tool in different ethnic groups and more refined consideration of family history should be explored. While FAMCAT may aid case finding, implementation requires information on the costeffectiveness of additional health services to investigate, diagnose and manage case ascertainment in those identified as likely to have FH.

\section{INTRODUCTION}

The National Health Service (NHS) Long Term Plan is committed to reducing cardiovascular disease with an ambition to prevent 150000 strokes, heart attacks and dementia cases over 10 years by detecting and treating risk factors including hypercholesterolaemia. ${ }^{1}$ Ischaemic heart disease (IHD) and strokes are among the most common causes of death in the $\mathrm{UK}^{2}$ with particularly high risks where the median age-standardised prevalence of hypercholesterolaemia $(>6.2 \mathrm{mmol} / \mathrm{L})$ exceeds $20 \%{ }^{3}$ The Global Burden of Disease Study and the
WHO Global Action Plan highlight that reduction of premature cardiovascular mortality is an international priority. ${ }^{4}$

Familial hypercholesterolaemia $(\mathrm{FH})$ is a genetic disorder characterised by elevated serum lowdensity lipoprotein cholesterol (LDL-C). ${ }^{67}$ In individuals of European descent, $\mathrm{FH}$ is associated with a 10 -fold greater lifetime risk of IHD and early death. ${ }^{8}$ Diagnosis is through clinical evaluation with validated diagnostic criteria (Simon Broome (SB) or Dutch Lipid Clinic Network (DLCN)) and consideration of genetic testing. ${ }^{9}$ Global cardiovascular risk scores are not applicable to patients with $\mathrm{FH}$ as they are already at high risk of IHD. ${ }^{810}$ Evidence supports early treatment in substantially reducing the risk of FH-related IHD and mortality. For patients with an inadequate response to standard therapies, there are expanded options from secondary care including PCSK9 inhibitors and new-in-class drugs. ${ }^{11-14}$ However, over $75 \%$ of estimated FH cases are undiagnosed ${ }^{1516}$ representing a missed opportunity to reduce the burden of cardiovascular disease.

Existing approaches to case finding of $\mathrm{FH}$ in primary care are suboptimal. The National Institute of Clinical Excellence advises assessment of people considered at high risk of $\mathrm{FH}$ based on total cholesterol levels or reported family history. ${ }^{10}$ Time and resource constraints in primary care precludes application of the SB and DLCN assessment consistently and completely in large numbers of patients. Therefore, current approaches to case finding are associated with significant inaccuracies and have the potential for underdiagnosis of $\mathrm{FH}$ and referral of high numbers of false positives.

The FH Case Ascertainment Tool (FAMCAT) is an externally validated case finding tool to identify individuals likely to have $\mathrm{FH}$ through systematic searching of routine primary care records for lipid profiles and other contributory variables. ${ }^{1718}$ Subsequent targeting of detailed clinical assessments to those at highest risk could enable more appropriate use of limited clinical resources, greater accuracy in identification of cases and improvement in case finding coverage. ${ }^{19}{ }^{20}$ Estimates of the cohort size allow for service planning and commissioning intentions, including primary care workload, demand for genetic testing and development of specialist clinics. 


\section{OBJECTIVE}

In this study, we retrospectively applied the FAMCAT to an unselected population of over 770000 primary care patients aged 18-65 years in East London, UK, using routinely collected primary care data. We report on the risk stratification of the population by FAMCAT and the number of cases identified as likely to have $\mathrm{FH}$, requiring further clinical assessment.

\section{METHODS}

\section{Study setting}

The analysis dataset included all primary care patients aged 18-65 years registered with general practitioners within three Clinical Commissioning Groups (CCGs) in East London. This comprised 127 practices (City and Hackney, $n=42$; Newham, $\mathrm{n}=50$; Tower Hamlets, $\mathrm{n}=35$ ), which use the Egton Medical Information Systems (EMIS) electronic health record. Compared with UK averages, this inner urban population has a greater proportion of individuals from black, South Asian and minority ethnic groups, younger average age, and higher levels of socioeconomic deprivation. In these CCGs, implementation of primary and secondary cardiovascular disease prevention strategies is higher than the national average. However, local levels of cardiovascular morbidities, in particular, premature cardiovascular disease, are ranked in the top $10 \%$ in the UK. ${ }^{21}$

\section{Defining the study population}

We included men and women aged 18-65 years old registered with a participating practice at the time of data extraction (01 July 2019). As FH is associated with premature IHD, we set the upper age limit as 65 years old. De-identified data based on Read codes in EMIS records were extracted centrally by the Clinical Effectiveness Group, Queen Mary University of London, including age, sex, ethnicity, clinical conditions (online supplemental table 1) and social deprivation. Deprivation was defined by national 2015 Index of Multiple Deprivation (IMD) quintiles derived from a geographical area comprising approximately 150 households. Blood pressure (BP) and smoking status were defined based on their most recent records. Ethnic group is selfreported and recorded in the health records and then categorised as black ethnicity including black African, Caribbean and black British; South Asian including Bangladeshi, Pakistani, Indian and other Indian subcontinent; white including white British and European; and other ethnic group including missing or not stated.

\section{Definition of the FAMCAT variables}

The FAMCAT score was devised and externally validated by Weng et al. ${ }^{17}$ In this study, we matched our definitions of the FAMCAT variables as closely as possible with that of the original (online supplemental table 2). For cholesterol, we considered the highest ever recorded value and if both total cholesterol and LDL-C were available, we gave preference to LDL-C. The highest triglyceride measured within 5 years of the highest cholesterol was used. In cases of missing triglyceride and/or cholesterol data, we used the mean value of the analysis sample based on patient's sex, age group of either $<40$ years or $\geq 40$ years and the IHD status. In alignment with Weng et al, ${ }^{17}$ outlying observations of cholesterol and triglyceride levels and data entry errors were excluded. We classed levels as 'untreated' if there was no record of prescription for lipid-lowering drugs (statin, fibrate, bile acid sequestrant, nicotinic acid) in the 90 days prior to cholesterol measurement. We categorised potency of lipid-lowering therapy into low (fluvastatin or pravastatin $\leq 40 \mathrm{mg}$ /day; simvastatin $\leq$
Table 1 Characteristics of the study population aged 18-65 years and the characteristics of the FAMCAT derivation cohort aged 16 years or above

\begin{tabular}{|c|c|c|}
\hline & \multirow{2}{*}{$\frac{\text { Study population }}{\mathrm{n}(\%) \text { or mean (SD) }}$} & \multirow{2}{*}{ 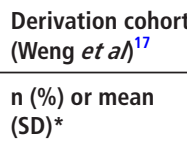 } \\
\hline & & \\
\hline Total & 777128 & 2228562 \\
\hline Age (years), mean (SD)† & $37.2(11.6)$ & $49.5(16.7)$ \\
\hline $\begin{array}{l}\text { Age during cholesterol measurement } \\
\text { (years), mean }(S D) \neq \S\end{array}$ & $35.7(10.8)$ & $57(16.3)$ \\
\hline \multicolumn{3}{|l|}{ Gender, n (\%) } \\
\hline Male & $372471(47.9)$ & $1083539(48.6)$ \\
\hline Female & $404657(52.1)$ & $1145023(51.4)$ \\
\hline Ethnicity, n (\%) & & Not available \\
\hline White & 308694 (39.7) & \\
\hline South Asian & $201957(26.0)$ & \\
\hline Black & $104138(13.4)$ & \\
\hline Other & $60601(7.8)$ & \\
\hline Unknownף & $101738(13.1)$ & \\
\hline IMD (national quintiles), $\mathrm{n}(\%)$ & & Not available \\
\hline Quintile 1 (least deprived) & $5555(0.7)$ & \\
\hline Quintile 2 & $16318(2.1)$ & \\
\hline Quintile 3 & $50812(6.5)$ & \\
\hline Quintile 4 & $323883(41.7)$ & \\
\hline Quintile 5 (most deprived) & $379446(48.8)$ & \\
\hline \multicolumn{3}{|l|}{ Lipid profile, mean (SD) } \\
\hline $\begin{array}{l}\text { Highest total cholesterol recorded, } \\
\mathrm{mmol} / \mathrm{L}^{* *}\end{array}$ & $5.3(1.2)$ & $5.8(1.3)$ \\
\hline $\begin{array}{l}\text { Highest LDL cholesterol recorded, } \\
\mathrm{mmol} / \mathrm{L} \dagger \dagger\end{array}$ & $3.5(1.1)$ & $3.6(1.1)$ \\
\hline $\begin{array}{l}\text { Triglycerides during cholesterol } \\
\text { measurement, } \mathrm{mmol} / \mathrm{L} \neq \neq^{\S \S}\end{array}$ & $1.7(1.3)$ & $1.7(1.2)$ \\
\hline \multicolumn{3}{|l|}{$\begin{array}{l}\text { Lipid-lowering drug usage at time of } \\
\text { cholesterol measurement, } n(\%)\end{array}$} \\
\hline $\begin{array}{l}\text { Prescribed fibrate, bile acid sequestrant } \\
\text { or nicotinic acid }\end{array}$ & $730(0.1)$ & $9817(0.4)$ \\
\hline Prescribed low-potency statin & $754(0.1)$ & $37799(1.7)$ \\
\hline Prescribed medium-potency statin & $21344(2.8)$ & $125315(5.6)$ \\
\hline Prescribed high-potency statin & $33034(4.3)$ & $35582(1.6)$ \\
\hline \multicolumn{3}{|l|}{ Family history, n (\%) } \\
\hline $\begin{array}{l}\text { Family history of familial } \\
\text { hypercholesterolaemia }\end{array}$ & $3440(0.4)$ & $12985(0.6)$ \\
\hline Family history of raised cholesterol & $10176(1.3)$ & $8796(0.4)$ \\
\hline Family history of myocardial infarction & $152155(19.6)$ & $71596(3.2)$ \\
\hline Pre-existing coronary heart disease, $\mathrm{n}(\%)$ & $7950(1.0)$ & Not available \\
\hline $\begin{array}{l}\text { Premature onset coronary heart disease } \\
(<60 \text { years), } \mathrm{n}(\%)\end{array}$ & $6444(0.8)$ & Not available \\
\hline Current smoker, n (\%) & $157549(20.3)$ & Not available \\
\hline Diabetes, n (\%) & $42844(5.5)$ & 285765 (12.8) \\
\hline Hypertension, n (\%) & $59215(7.6)$ & Not available \\
\hline Familial hypercholesterolaemia, n (\%) & $16573(2.1)$ & Not available \\
\hline Stroke TIA, n (\%) & $3500(0.5)$ & Not available \\
\hline Kidney disease, $n(\%)$ & $11629(1.5)$ & $261458(11.7)$ \\
\hline \multicolumn{3}{|c|}{ 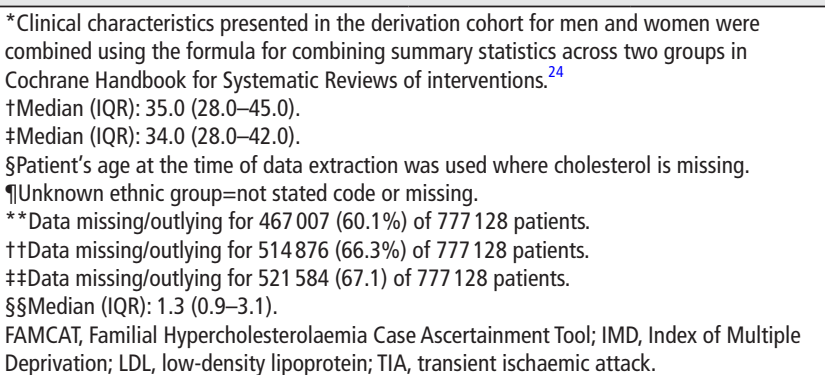 } \\
\hline
\end{tabular}


$10 \mathrm{mg} /$ day), medium (fluvastatin or pravastatin $80 \mathrm{mg} /$ day; simvastatin $20 \mathrm{mg} /$ day or $40 \mathrm{mg} /$ day; atorvastatin $\leq 10 \mathrm{mg} /$ day; rosuvastatin $5 \mathrm{mg}$ ), or high (simvastatin $80 \mathrm{mg}$; atorvastatin $\geq$ $20 \mathrm{mg} /$ day; rosuvastatin $\geq 10 \mathrm{mg} /$ day) intensity.

\section{Calculation of FAMCAT risk}

FH risk was calculated through application of the FAMCAT regression equations to our study population with variables defined as outlined. Estimates were based on probability thresholds of both 1 in 250 and 1 in 500 population prevalence of $\mathrm{FH}^{16}{ }^{22}$ We categorised risk stratification resulting from this analysis as unlikely, may or likely to have FH. A relative population risk of $<1$ indicated the individual was unlikely to have $\mathrm{FH}$, a relative population risk from 1 to 5 indicated the individual may have $\mathrm{FH}$, and a relative population risk of $>5$ indicated the individual is likely to have FH. We present these results for the whole cohort and separately for individuals with premature IHD (onset before age 65 years).

We performed a sensitivity analysis without imputations using the other variables to estimate the risk of $\mathrm{FH}$ where cholesterol and triglyceride were missing (see online supplemental table 3).

\section{Patient and public involvement}

Patients and the public were not involved in the design, conduct or outcome of this work.

\section{RESULTS}

\section{Baseline population characteristics}

The analysis sample comprised 404657 women and 372471 men with mean age (SD) of 37.2 (11.6) years (range 18-65 years). The population was ethnically diverse including white (308 694, 39.7\%), South Asian (201 957, 26.0\%), and black Caribbean and African $(104$ 138, 13.4\%) ethnic groups (table 1). Levels of deprivation were high relative to UK national averages with $>90 \%$ of patients in the two most deprived IMD quintiles. The prevalence of smoking, diabetes, hypertension, chronic kidney disease (CKD) and stroke were 157549 (20.3\%), 42844 (5.5\%), 59215 (7.6\%), $11629(1.0 \%)$ and 3500 (0.5\%), respectively. Prevalence of pre-existing IHD was 7950 (1.0\%), with IHD recorded prior to the age 60 years in $6444(81 \%)$ of these patients.

\section{Level of recording of required data}

Table 2 shows the level of data recording. Cholesterol was recorded for $82.5 \%$ (6558) of patients with IHD and $39.5 \%$ (303 921) of patients without IHD. Of the 16573 with coded FH, $14.5 \%(2,397)$ did not have cholesterol recorded. Recording of cholesterol was more frequent for individuals aged 40 years and older.

\section{FAMCAT risk applied to the whole cohort}

Within the study population (777 128), 11736-23 798 (1.5\%$3.1 \%$ ) patients were estimated to be likely to have $\mathrm{FH}$, depending on the prevalence assumed (figure 1). A total of 36630-80 $372(4.7 \%-10.3 \%)$ patients were estimated they may have $\mathrm{FH}$ (table 3). For individuals with IHD (7950), 552-938 (6.9\%$11.8 \%)$ were likely to have FH and 1253-1842 (15.8\%-23.2\%) may have FH. For those without IHD (769 178), 11 184-22 860 (1.5\%-3.0\%) were likely to have FH. In total, between 48366 and 104170 people were estimated that they may or were likely to have $\mathrm{FH}$ who may need further investigation (between $6.2 \%$ and $13.4 \%$ of our total cohort). The computation of FAMCAT risk with and without missing data for both IHD and non-IHD
Table 2 Completeness of data recording

\begin{tabular}{|rrr}
\hline & N & $\%$ \\
\hline Age 18-65 years & 777128 & \\
\hline Cholesterol recorded & \\
\hline BP recorded & 310436 & 40.1 \\
\hline IHD & 676855 & 87.1 \\
\hline Age 18-39 years & 7950 & 1.0 \\
\hline Cholesterol recorded* & 490482 & \\
\hline BP recorded & 106404 & 21.7 \\
\hline IHD & 399078 & 81.4 \\
\hline Age 40-65 years & 252 & 0.1 \\
\hline Cholesterol recorded & \\
\hline BP recorded & 286646 & \\
\hline IHD & 204032 & 71.2 \\
\hline With familial hypercholesterolaemia & 277070 & 96.7 \\
\hline Cholesterol recorded & 7698 & 2.7 \\
\hline BP recorded & 16573 & \\
\hline IHD & 14173 & 85.5 \\
\hline With IHD & 16522 & 99.7 \\
\hline Cholesterol recorded* & 1240 & 7.5 \\
\hline BP recorded & 7950 & \\
\hline Without IHD & 6556 & 82.5 \\
\hline Cholesterol recorded* & 7938 & 99.8 \\
\hline BP recorded & 769178 & \\
\hline "Patis wh non & 303880 & 39.5 \\
\hline
\end{tabular}

*Patients with non-missing or non-outlying LDL or total cholesterol values.

$B P$, blood pressure; IHD, ischaemic heart disease; LDL, low-density lipoprotein.

resulted in changes of less than $1 \%$ in all categories of risk (online supplemental table 3).

\section{FAMCAT risk in ethnic groups}

Table 4 describes risk of FH by ethnic group. A total of $39.7 \%$ of the study population were in white ethnic groups. Among individuals of white ethnicity who had IHD, 7.8\%-13.2\% were estimated they were likely to have $\mathrm{FH}$, compared with $6.8 \%-11.6 \%$ of South Asians and 5.2\%-9.9\% of black African/Caribbean individuals. In white ethnic groups without IHD, 1.2\%-2.5\% were likely to have FH compared with $2.5 \%-4.8 \%$ in South Asian and 1.1\%-2.8\% in black African/Caribbean groups.

\section{DISCUSSION}

In this large study of 777128 primary care patients, we demonstrated the feasibility of application of the FAMCAT algorithm to aid case finding of $\mathrm{FH}$ using routinely recorded primary care data. Our analysis identified between 48366 and 104170 $(6.2 \%-13.4 \%)$ people who may or were likely to have $\mathrm{FH}$ who would therefore warrant further assessment and potentially genetic testing and specialist services. These findings have important implications for care and service planning in primary and secondary care.

In our population, 1 in 30 to 1 in 100 were likely to have $\mathrm{FH}$ according to FAMCAT risk stratification, compared with estimates of disease prevalence from 1 in 250 to 1 in $500 .{ }^{1622}$ Among individuals with pre-existing IHD, this increased to $6.9 \%$ $11.8 \%$, suggesting that targeting testing and treatment for $\mathrm{FH}$ in this latter group would have a higher positive case yield. ${ }^{19} 20$

A total of $2.1 \%$ of this population were found to have a code for $\mathrm{FH}$, which is higher than previously reported estimates of $\mathrm{FH}$ prevalence. The prevalence in our study may be inflated due to coding errors where patients with high cholesterol and/or family history of high cholesterol were incorrectly coded as ' $\mathrm{FH}$ ' 


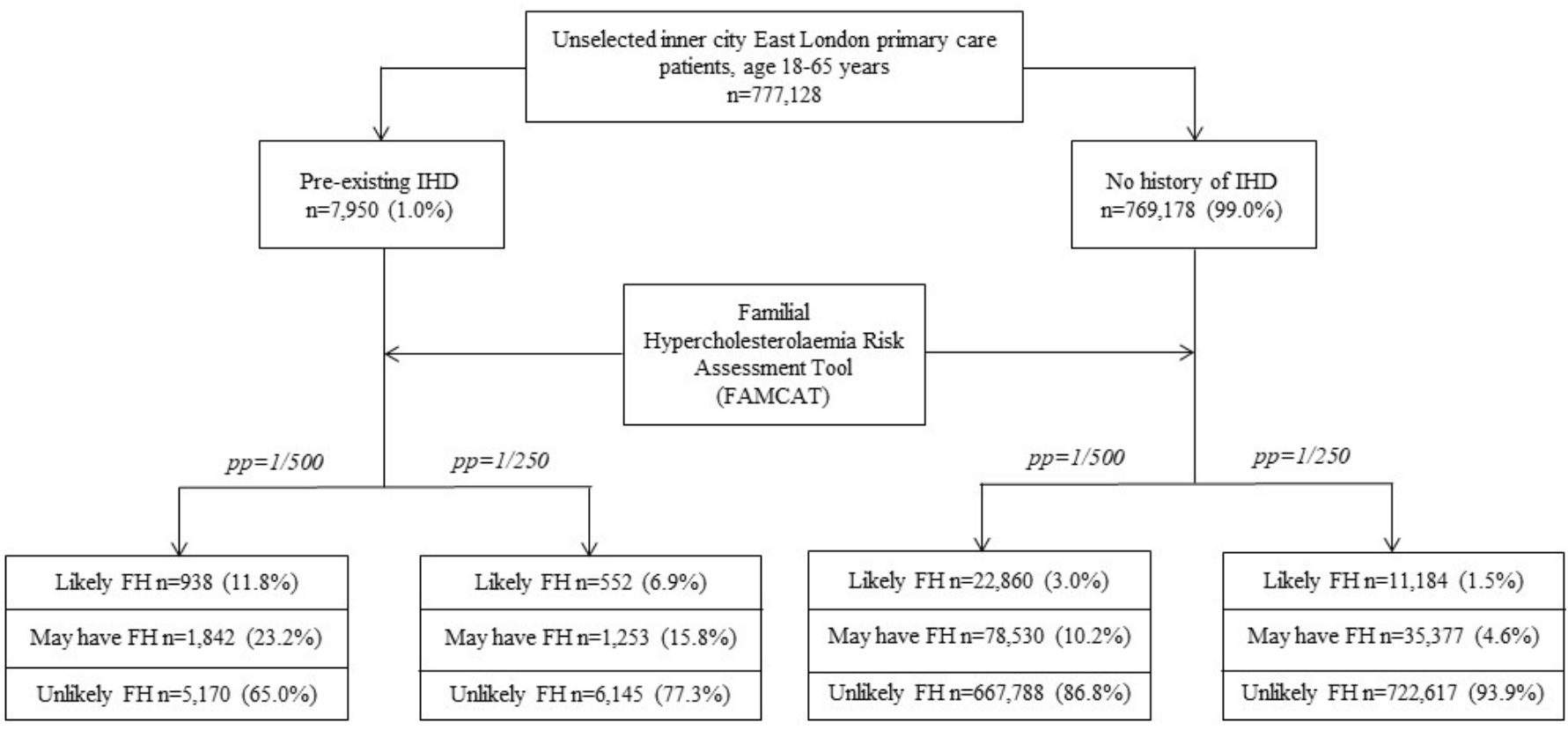

Figure 1 Risk of familial hypercholesterolaemia (FH) in inner East London calculated using FAMCAT algorithm, assuming population prevalence of 1 in 500 and 1 in 250. IHD, ischaemic heart disease; PP, population prevalence.

without further scrutiny to determine a correct diagnosis. Of those coded as having FH, 47.5\% were identified by FAMCAT as unlikely to have FH (online supplemental table 4). Further clarification on the accuracy of these diagnoses is needed. This would require a case note review, which was not available in this study.

\section{FAMCAT in ethnic groups}

The risk of FH varied by ethnicity. In those with IHD, FH likelihood was highest in white and lowest in black ethnic groups. In people without IHD, the FH likelihood was highest in South

Table 3 Predicted number of cases of familial hypercholesterolaemia assuming population prevalence of 1 in 500 and 1 in 250

\begin{tabular}{|c|c|c|c|c|}
\hline & \multicolumn{2}{|l|}{$1 / 500$} & \multicolumn{2}{|l|}{$1 / 250$} \\
\hline & $\mathrm{N}$ & $\%$ & $\mathrm{~N}$ & $\%$ \\
\hline All patients & 777128 & & 777128 & \\
\hline $\begin{array}{l}\text { Likely to have familial } \\
\text { hypercholesterolaemia }\end{array}$ & 23798 & 3.1 & 11736 & 1.5 \\
\hline $\begin{array}{l}\text { May have familial } \\
\text { hypercholesterolaemia }\end{array}$ & 80372 & 10.3 & 36630 & 4.7 \\
\hline $\begin{array}{l}\text { Unlikely to have familial } \\
\text { hypercholesterolaemia }\end{array}$ & 672958 & 86.6 & 728762 & 93.8 \\
\hline Patients with IHD & 7950 & & 7950 & \\
\hline $\begin{array}{l}\text { Likely to have familial } \\
\text { hypercholesterolaemia }\end{array}$ & 938 & 11.8 & 552 & 6.9 \\
\hline $\begin{array}{l}\text { May have familial } \\
\text { hypercholesterolaemia }\end{array}$ & 1842 & 23.2 & 1253 & 15.8 \\
\hline $\begin{array}{l}\text { Unlikely to have familial } \\
\text { hypercholesterolaemia }\end{array}$ & 5170 & 65.0 & 6145 & 77.3 \\
\hline Patients without IHD & 769178 & & 769178 & \\
\hline $\begin{array}{l}\text { Likely to have familial } \\
\text { hypercholesterolaemia }\end{array}$ & 22860 & 3.0 & 11184 & 1.5 \\
\hline $\begin{array}{l}\text { May have familial } \\
\text { hypercholesterolaemia }\end{array}$ & 78530 & 10.2 & 35377 & 4.6 \\
\hline $\begin{array}{l}\text { Unlikely to have familial } \\
\text { hypercholesterolaemia }\end{array}$ & 667788 & 86.8 & 722617 & 93.9 \\
\hline
\end{tabular}

Asian and lowest in black groups. This may suggest that $\mathrm{FH}$ is a more important factor in development of IHD for white ethnicities. Alternatively, our observations may indicate lower sensitivity of FAMCAT in detecting FH in black and South Asian ethnic groups. Indeed, lower predictive accuracy of the FAMCAT in these groups has been previously highlighted. ${ }^{18}$ Further research is needed on potential ethnicity differential disease patterns of $\mathrm{FH}$ and the performance of risk prediction tools including the FAMCAT for informed clinical application in ethnically diverse populations.

\section{Comparison with FAMCAT validation population}

The FAMCAT validation population ${ }^{17}$ ran from 1999 to 2013 , while our population was more contemporaneous comprising those currently registered in 2019. Our population was, on average, younger than that studied by Weng et al, with a mean age of 37.2 vs 49.5 years. ${ }^{17}$ The average age at first cholesterol

\begin{tabular}{|c|c|c|c|c|c|}
\hline & \multirow[b]{2}{*}{ Total } & \multicolumn{2}{|l|}{ FH $1 / 500$} & \multicolumn{2}{|l|}{ FH $1 / 250$} \\
\hline & & Number & $\%$ & Number & $\%$ \\
\hline Patients with IHD & 7950 & 938 & 11.8 & 552 & 6.9 \\
\hline White & 2562 & 337 & 13.2 & 199 & 7.8 \\
\hline South Asian & 3718 & 431 & 11.6 & 251 & 6.8 \\
\hline Black African/Caribbean & 776 & 77 & 9.9 & 40 & 5.2 \\
\hline Other & 438 & 45 & 10.3 & 32 & 7.3 \\
\hline Unknown* & 456 & 48 & 10.5 & 30 & 6.6 \\
\hline Patients without IHD & 769178 & 22860 & 3.0 & 11184 & 1.5 \\
\hline White & 306132 & 7640 & 2.5 & 3591 & 1.2 \\
\hline South Asian & 198239 & 9571 & 4.8 & 5046 & 2.5 \\
\hline Black African/Caribbean & 103362 & 2850 & 2.8 & 1157 & 1.1 \\
\hline Other & 60163 & 1309 & 2.2 & 642 & 1.1 \\
\hline Not stated/missing* & 101282 & 1490 & 1.5 & 748 & 0.7 \\
\hline
\end{tabular}

*Unknown ethnic group=not stated code or missing.

FAMCAT, Familial Hypercholesterolaemia Case Ascertainment Tool; FH, familial hypercholesterolaemia; IHD, ischaemic heart disease. 
measurement was higher in the Weng et al cohort (57 vs 35.7 years) as was the prevalence of diabetes and CKD $(12.8 \%$ vs $5.5 \%, 11.7 \%$ vs $1.5 \%$ ), which is likely to be due to older age of participants in their cohort. There is a difference in the mean total cholesterol, while the mean LDL is similar between our study populations. However, the standard deviations of the means overlap, indicating that this difference is not statistically significant. Our population had a higher proportion of people with a recorded family history of myocardial infarction: $19.6 \%$ vs $3.2 \%$ in the Weng et al cohort. Recording of family history is integral to the national NHS Health Check programme in East London which may be the main reason for high levels of documentation, though the accuracy of these recordings is unknown. ${ }^{23}$ FAMCAT only considers family history of IHD as a binary score and does not consider kinship or prematurity of onset. The relevance of accurate family history of premature IHD is an outstanding issue for further research as it is an essential element of further case identification. A comparison cannot be made between ethnicity and deprivation as they were not reported in the Weng et al paper. In keeping with Weng et al, patients on ezetimibe alone had their levels classed as 'untreated'. We also observed less missingness in all variables of interest for individuals aged over 40 years, corresponding to the 40-74 years of eligibility threshold for the NHS Health Check since 2009 and the inclusion of BP in the national Quality and Outcomes Framework for people over 40 years since 2013 .

\section{Implications for clinical practice}

The 23798 patients who were likely to have FH represent a large group of patients within which $\mathrm{FH}$ cases may exist, and these have been relatively easily identified through a datadriven approach. Use of the FAMCAT algorithm could allow primary care practices to generate a list of patients who may have $\mathrm{FH}$, where the diagnosis has not yet been considered or excluded, using routinely recorded data. These at-risk individuals could be reviewed in more detail to determine an up-todate FAMCAT risk and, if appropriate, clinical evaluation using the DLCN or SB criteria and genetic testing to confirm their disease status.

FAMCAT has showed a high degree of discrimination (area under the receiver operating curve 0.832 , 95\% CI 0.820 to $0.845)$. Assuming a population frequency of 1 in 500, FAMCAT had a sensitivity of $84 \%$ (1028 predicted vs 1219 observed cases) and specificity of 60\% (443949 predicted vs 745781 observed non-cases), with a positive predictive value of $0.84 \%$ and a negative predictive value of $99.2 \% .^{18}$ In other words, for every 119 people likely to have $\mathrm{FH}$, after further investigation, 1 person would be identified with $\mathrm{FH}$ and 118 would not have genetically confirmed FH but would nevertheless require clinical advice on whether further treatment was required based on the family history and clinical findings.

This study demonstrates that other localities could potentially use FAMCAT to aid FH case finding, though not all areas have the digital maturity to run algorithms across the entire local population. The application of FAMCAT is likely to generate substantial additional workload for primary and secondary care services. Therefore, it is imperative to consider infrastructure requirements to accommodate the expected increase in demand in both community and secondary care settings. For instance, development of dedicated community $\mathrm{FH}$ facilities may be of value to reduce the burden on existing hospital lipid clinics. Such large-scale changes to specialist investigations would require evidence of cost-effectiveness and substantial changes to current care pathways.

Those who have not had an ischaemic cardiac event but are deemed likely to have FH by FAMCAT represent a group who may not otherwise have been identified before an index myocardial infarction or stroke, and for whom testing and treatment would play an important part in positively altering their disease trajectory. An FH diagnosis will help ensure they have appropriate treatment, and is also important for their families and cascade testing. In those who have had a cardiac event, confirmation of FH would have similar implications including for firstdegree relatives.

\section{Limitations}

FAMCAT is not diagnostic, it merely applies a risk estimate. As seen in this paper, this approach generates a large cohort who need further scrutiny, first in primary care with a detailed family history and examination, then in secondary care for genetic testing and clinical advice. The FAMCAT algorithm generates substantial numbers at high $\mathrm{FH}$ risk for further investigation and management, and this process has yet to be assessed for cost-effectiveness.

Calculating individual $\mathrm{FH}$ risks without cholesterol and triglyceride measurements assumes values that fall into the ideal category in the FAMCAT algorithm. This could lead to incorrect estimates. Hence, we imputed missing values using population means for IHD and non-IHD groups. This approach artificially reduces the overall variability of missing variables. In studies where the primary purpose is hypothesis testing, this approach to imputation may lower the threshold for achieving statistical significance. However, this limitation is less important for this study, as the purpose of our work is demonstration of feasibility and description of the FAMCAT.

Use of the FAMCAT relies on recording of coded data including BP, cholesterol and family history. There was less

\section{Key messages}

What is already known on this subject?

- Underdiagnosis of familial hypercholesterolaemia (FH) represents a significant missed opportunity for prevention of coronary artery disease and premature death. The FH Risk Ascertainment Tool (FAMCAT) is designed to improve case finding in primary care but has not been studied in unselected primary care settings.

\section{What might this study add?}

- The original FAMCAT Study used a national dataset of selected volunteer practices to estimate likelihood of $\mathrm{FH}$ from routine data in primary care electronic health records. Our study applies FAMCAT to a large, unselected and ethnically diverse urban population. We estimate the number of people with possible $\mathrm{FH}$ and their demographic and clinical characteristics.

How might this impact on clinical practice?

- We demonstrated that FAMCAT could be feasibly applied to routine primary care data to enhance identification of individuals with $\mathrm{FH}$. This information informs planning of health service provision and highlights recording of family history and ethnicity as topics for further research and improvement. 
missingness of these variables for individuals aged over 40 years old, notably of cholesterol. This is likely due to the NHS Health Check and suggests this could also be an opportunity to estimate the FAMCAT risk. A total of $60.5 \%$ of patients without IHD and $14.5 \%$ with IHD did not have a record of cholesterol measurement. A complete lipid profile is advisable for optimal accuracy of FAMCAT.

\section{CONCLUSION}

We were able to implement the FAMCAT algorithm across entire localities to estimate likely numbers of patients requiring investigation for $\mathrm{FH}$ and assist commissioners and health service providers to determine these approaches. However, further research on the external validity in different settings and populations is warranted for the tool to be applied more widely. The recording of key variables including first-degree family history of premature IHD and the missing data requires improvement for use in service settings. Such data-driven approaches have the potential to improve detection of $\mathrm{FH}$ in the general population and reduce cardiovascular morbidity and mortality, but evidence of cost-effectiveness for full implementation of such a pathway is currently lacking.

Acknowledgements We are grateful to the general practitioners and their practice teams for allowing the use of their patient records, to the Clinical Effectiveness Group for providing access to their curated high-quality dataset and to the population in East London from whom the data are derived. This work was supported by Barts Charity and Health Data Research UK, an initiative funded by UK Research and Innovation, Department of Health and Social Care (England) and the devolved administrations, and leading medical research charities.

Contributors JR and CC conceived the study. CW conducted the data extraction and the analysis. All authors contributed to the planning of the study and the manuscript.

Funding This study received no specific funding. JR, SR, CW and CC are employed by Queen Mary University of London. AT was and RSP is employed by Barts Health Trust. SR was supported by Barts Charity, JR and CW were supported by Health Data Research UK. ZR-E is supported by a British Heart Foundation Clinical Research Training Fellowship (FS/17/81/33318).

Competing interests RSP reports personal fees from SANOFI, grants from AMGEN, and personal fees from NOVARTIS, outside the submitted work.

Patient consent for publication Not required.

Ethics approval This study is based on de-identified information obtained from routinely compiled general practitioner electronic health records and did not require ethics committee approval.

Provenance and peer review Not commissioned; externally peer reviewed.

Data availability statement Data are available upon reasonable request. All data relevant to the study are included in the article or uploaded as supplemental information. Data are extracted from patient record systems held by GP practices. Outputs of the data extracted are collated and in the format of tables within the paper or in supplemental information.

Supplemental material This content has been supplied by the author(s). It has not been vetted by BMJ Publishing Group Limited (BMJ) and may not have been peer-reviewed. Any opinions or recommendations discussed are solely those of the author(s) and are not endorsed by BMJ. BMJ disclaims all liability and responsibility arising from any reliance placed on the content. Where the content includes any translated material, BMJ does not warrant the accuracy and reliability of the translations (including but not limited to local regulations, clinical guidelines, terminology, drug names and drug dosages), and is not responsible for any error and/or omissions arising from translation and adaptation or otherwise.

ORCID iDs

Chris Carvalho http://orcid.org/0000-0002-4114-9210

Zahra Raisi-Estabragh http://orcid.org/0000-0002-7757-5465

Stuart Rison http://orcid.org/0000-0003-3289-6668

Riyaz S Patel http://orcid.org/0000-0003-4603-2393
Adam Timmis http://orcid.org/0000-0003-1419-112X

John Robson http://orcid.org/0000-0001-6889-0415

\section{REFERENCES}

1 NHS Long Term Plan [Internet]. NHS England, 2019. Available: https://www. longtermplan.nhs.uk/publication/nhs-long-term-plan/ [Accessed 9 Feb 2019].

2 British Heart Association. Heart statistics [Internet]. BHF, 2019. Available: https:// www.bhf.org.uk/what-we-do/our-research/heart-statistics

3 Timmis A, Townsend N, Gale CP, et al. European Society of cardiology: cardiovascular disease statistics 2019. Eur Heart J 2020:41:12-85.

4 Roth GA, Abate D, Abate KH, et al. Global, regional, and national age-sex-specific mortality for 282 causes of death in 195 countries and territories, 1980-2017: a systematic analysis for the global burden of disease study 2017. The Lancet 2018;392:1736-88

5 World Health Organization. Global action plan for the prevention and control of noncommunicable diseases: 2013-2020, 2013. Available: http://apps.who.int/iris/ bitstream/10665/94384/1/9789241506236 eng.pdf [Accessed 4 Aug 2020].

6 Bouhairie VE, Goldberg AC. Familial hypercholesterolemia. Cardiol Clin 2015:33:169-79.

7 Marks D, Thorogood M, Neil HAW, et al. A review on the diagnosis, natural history, and treatment of familial hypercholesterolaemia. Atherosclerosis 2003;168:1-14.

8 Mach F, Baigent C, Catapano AL. ESC/EAS guidelines for the management of dyslipidaemias: lipid modification to reduce cardiovascular risk. Eur Heart J 2019;2019:1-78

9 Risk of fatal coronary heart disease in familial hypercholesterolaemia. scientific Steering Committee on behalf of the Simon Broome register group. BMJ 1991;303:893-6.

10 DeMott K, Nherera L, Shaw E. Clinical guidelines and evidence review for familial hypercholesterolaemia: the identification and management of adults and children with familial hypercholesterolaemia NICE Clinical Guidline CG 71. [accessed 14/5/2021] 2008 https://www.nice.org.uk/guidance/cg71/evidence/full-guideline-pdf241917805

11 Austin MA, Zimmern RL, Humphries SE. High "population attributable fraction" for coronary heart disease mortality among relatives in monogenic familial hypercholesterolemia. Genet Med 2002;4:275-8.

12 lacobucci G. Inclisiran: UK to roll out new cholesterol lowering drug from next year. BMJ 2020;368:m139 https://www.bmj.com/content/368/bmj.m139

13 Raal FJ, Kallend D, Ray KK, et al. Inclisiran for the treatment of heterozygous familial hypercholesterolemia. N Engl J Med 2020;382:1520-30.

14 Robinson JG, Farnier M, Krempf M, et al. Efficacy and safety of alirocumab in reducing lipids and cardiovascular events. N Engl J Med 2015:372:1489-99.

15 Neil HA, Hammond T, Huxley R, et al. Extent of underdiagnosis of familial hypercholesterolaemia in routine practice: prospective registry study. BMJ 2000;321:148

16 Akioyamen LE, Genest J, Shan SD, et al. Estimating the prevalence of heterozygous familial hypercholesterolaemia: a systematic review and meta-analysis. BMJ Open 2017:7:e016461.

17 Weng SF, Kai J, Andrew Neil H, et al. Improving identification of familial hypercholesterolaemia in primary care: derivation and validation of the familial hypercholesterolaemia case ascertainment tool (FAMCAT). Atherosclerosis 2015;238:336-43.

18 Weng S, Kai J, Akyea R, et al. Detection of familial hypercholesterolaemia: external validation of the FAMCAT clinical case-finding algorithm to identify patients in primary care. Lancet Public Health 2019:4:e256-64.

19 National Institute for Health and Care Excellence. Familial hypercholesterolaemia: identification and management: Evidence reviews for case-finding, diagnosis and statin monotherapy. [Internet]. Familial hypercholesterolaemia: identification and management: Evidence reviews for case-finding, diagnosis and statin monotherapy. National Institute for Health and Care Excellence (UK), 2017. Available: https://www. ncbi.nlm.nih.gov/books/NBK550190/ [Accessed 19 Jan 2021].

20 Brett T, Qureshi N, Gidding S, et al. Screening for familial hypercholesterolaemia in primary care: time for general practice to play its part. Atherosclerosis 2018:277:399-406.

21 Public Health England. Primary Care CVD intelligence packs [Internet]. London, UK, 2019. Available: https://fingertips. phe.org.uk/profile/cardiovascular-disease-primarycare [Accessed 24 May 2020].

22 Nordestgaard BG, Chapman MJ, Humphries SE, et al. Familial hypercholesterolaemia is underdiagnosed and undertreated in the general population: guidance for clinicians to prevent coronary heart disease: consensus statement of the European atherosclerosis Society. Eur Heart J 2013;34:3478-90.

23 NHS England. NHS Health Check [Internet]. nhs.uk, 2017. Available: https://www.nhs. uk/conditions/nhs-health-check/ [Accessed 4 Aug 2020].

24 Higgins JP, Thomas J, Chandler J, et al. Cochrane Handbook for systematic reviews of interventions. John Wiley \& Sons, 2019. 